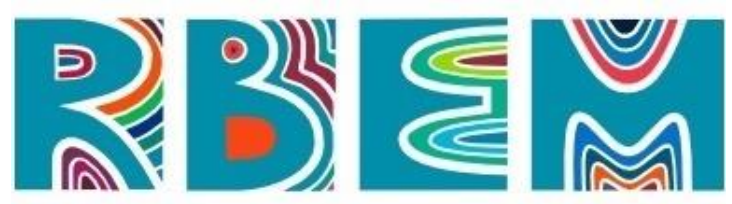

REVISTA BAIANA DE EDUCAÇÃO MATEMÁTICA

\title{
ARTIGO
}

do] https://doi.org/10.47207/rbem.v2i01.12159

\section{A Resolução de Problemas enquanto metodologia de ensino no Estágio Remoto Emergencial}

\author{
MENDUNI-BORTOLOTI, Roberta D' Angela \\ Universidade Estadual do Sudoeste da Bahia (UESB). Doutora em Educação. ORCID: https://orcid.org/0000- \\ 0002-2713-5699. E-mail: robertamenduni@uesb.edu.br. \\ OLIVEIRA, Kely Viviane Gonçalves \\ Colégio Matisse. Mestre em Ciências da Educação. ORCID: https://orcid.org/0000-0002-3924-3830. E-mail: \\ kely_vivi@yahoo.com.br.
}

\begin{abstract}
Resumo: Esse estudo é resultado de uma pesquisa qualitativa, cujo objetivo foi problematizar diferentes formas de resolução de um problema, estando em ambiente virtual, a partir dos registros propostos pelos licenciandos em matemática e estudantes do ensino fundamental. Tomamos como foco de análise as resoluções propostas por licenciandos em Matemática, na disciplina Estágio Supervisionado I e turmas de $6^{\circ}$ e $7^{\circ}$ anos do ensino fundamental de uma escola particular baiana. Propusemos uma situação problema para todos esses estudantes, sendo que para os licenciandos tivemos como foco utilizar a metodologia da resolução de problemas como metodologia de ensino, seguindo um roteiro específico. Para produção dos dados nos apoiamos na categorização, ou seja, a análise das diferentes formas de resolver o problema foram agrupadas conforme semelhanças. Ao analisar as resoluções dos estudantes do ensino fundamental, produzimos 3 categorias: 1) tentativa e erro; 2) álgebra e 3) resolução equivocada. Já para os licenciandos foram: 1) álgebra; 2) fixando valores e 3) progressão aritmética. Como resultados podemos afirmar que todos os envolvidos perceberam que as estratégias podem ser diversas, o que sugere os estudantes serem sujeitos da sua própria aprendizagem. Contudo, só faz sentido se as diferentes resoluções forem socializadas, assim perceberão a diversidade na forma de comunicá-las. Os licenciandos tinham a seu favor, um conhecimento matemático muito maior que os estudantes do ensino fundamental II, porém em nada esses ficaram a desejar, pois quando não tinham a técnica ou conhecimento matemático (linguagem matemática) eles usaram a lógica e comunicaram suas estratégias recorrendo a linguagem materna.

Palavras-chave: Estágio Supervisionado em Matemática. Ensino remoto. Resolução de Problemas. Metodologia de ensino.
\end{abstract}

\section{Problem Solving as a teaching methodology in the Emergency Remote Internship}

\begin{abstract}
This study is the result of a qualitative research whose objective was to problematize different ways of solving a problem in a virtual environment, basead on the records proposed by mathematics undergraduates and elementary school students. We took as analysis focus the resolutions proposed by undergraduate students in Mathematics, in the Supervised Internship discipline, and in the 6th and 7th grade classes of a private elementary school in the State of Bahia. We proposed a problemsituation for students and, for future teachers. In that situation, we focused on using the problem solving methodology as a teaching methodology, following a specific guide. For development of this study, we used the analysis of the different ways, grouped by similarities, to solve the problem.
\end{abstract}




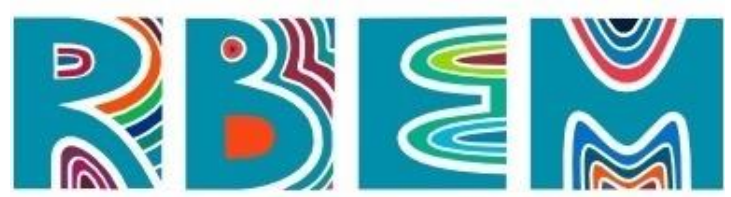

REVISTA BAIANA DE EDUCAÇÃO MATEMÁTICA

Analyzing the resolutions of the elementary school students, we produced three categories: 1) trial and error; 2) algebra and 3) wrong resolution. In the case of future teachers, the produced categories were: 1) algebra; 2) setting values and 3) arithmetic progression. We determine that each subject involved in this study realized that strategies may be different, suggesting that students are subjects of their own learning. However, that difference makes sense only if the resolutions are socialized, and therefore being able to perceive diversity in the way they communicate. Although future teachers have greater mathematical knowledge, elementary school students used Logic and communicated their strategies in their mother tongue.

Keywords: Supervised Internship in Mathematics. Remote teaching. Problem solving. Teaching methodology.

\section{La resolución de problemas como metodología docente en la Pasantía Remota de Emergencia}

Resumen: Este artículo es el resultado de una investigación cualitativa, cuyo objetivo fue problematizar diferentes formas de resolucuión de un problema, en un entorno virtual, a partir de los registros propuestos por los estudiantes de licenciatura y primaria em matemáticas. Tomamos como foco de análisis las resoluciones propuestas por estudiantes de pregrado en Matemáticas, en la disciplina Pasantía Supervisada I y en las clases de $6^{\circ}$ y $7^{\circ}$ grado de la escuela primaria en un colegio privado de Bahía. Propusimos una situación-problema para todos estos alumnos y, para los futuros profesores, nos centramos en utilizar la metodología de resolución de problemas como metodología de enseñanza, siguiendo un guión específico. Para la producción de datos, nos apoyamos en la categorización, es decir, los análisis de las diferentes formas de resolver el problema se agruparon por similitudes. Al analizar las resoluciones de los estudiantes de la escuela primaria, produjimos 3 categorías: 1) prueba y error; 2) álgebra y 3) resolución incorrecta. En cuanto a los futuros profesores, fueron: 1) álgebra; 2) configuración de valores y 3) progresión aritmética. Como resultado, podemos decir que todos los involucrados se dieron cuenta de que las estrategias pueden ser diferentes, lo que sugiere que los estudiantes son sujetos de su propio aprendizaje. Sin embargo, solo tiene sentido si se socializan las distintas resoluciones, para que perciban la diversidad en la forma de comunicarse. Los futuros profesores tenían a su favor, un conocimiento matemático mucho mayor que los alumnos de la Escuela Primaria II, pero no eran deseables, porque cuando no tenían la técnica ni los conocimientos matemáticos (lenguaje matemático) usaban la lógica y comunicaban sus estrategias en la lengua materna.

Palavras-Clave: Pasantía supervisada en matemáticas. Enseñanza remota. Solución de problemas. Metodología de la enseñanza.

\section{Introdução}

Há mais de um ano o Brasil e o mundo enfrentam desafios em diversas áreas como economia, saúde e educação, devido às mudanças ocasionadas pela COVID-19, doença causada pelo novo coronavírus.

Desde março de 2020 tivemos as aulas suspensas em todos país, retornando emergencialmente de forma remota, no estado da Bahia, em outubro (instituições públicas). A essa nova realidade atribuímos o nome de Ensino Remoto Emergencial, conhecido por ERE. 


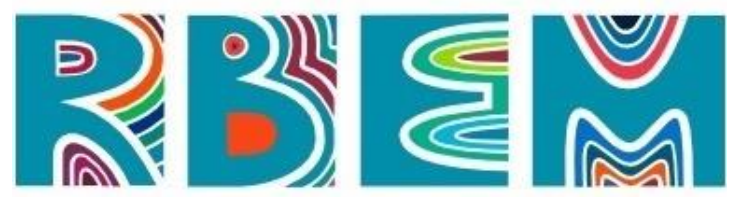

REVISTA BAIANA DE EDUCAÇÃO MATEMÁTICA

Apesar de toda dificuldade para professores, estudantes e profissionais da Educação, tivemos que nos readaptar e encontrar formas de ministrar as aulas, acompanhar os estudantes, realizar disciplinas como Estágio Supervisionado sem estarmos presencialmente em um espaço físico.

Na Universidade Estadual do Sudoeste da Bahia (UESB), nossa autonomia para decidirmos como realizar os estágios supervisionados foi garantida. De acordo a Resolução 098/2004 (CONSEPE) os estágios supervisionados podem ser realizados em três modalidades: ensino (obrigatoriamente), pesquisa e extensão (facultativamente). Nesse artigo discorreremos sobre o estágio supervisionado, no curso de licenciatura em matemática, na modalidade extensão, realizado no início de 2021.

O estágio na modalidade extensão no ERE foi compreendido, por nós (Colegiado de Matemática e professores envolvidos), como um período em que as discussões e reflexões sobre a prática de uma sala de aula seriam desenvolvidas na plataforma meet e a regência por meio de oficinas.

Diante dessa nova realidade, os licenciandos não teriam a oportunidade de acompanhar os estudantes de $6^{\circ}$ e $7^{\circ}$ anos em sala, observarem como esses resolveriam situações problematizadoras e a orientação do professor regente, como ocorre no estágio 足 modalidade ensino, vivenciado presencialmente.

Uma forma que encontramos de fazer com que os licenciandos conhecessem um pouco da realidade de uma sala de aula, especificamente como os estudantes resolvem questões sobre o conteúdo de matemática, foi convidar uma professora (segunda autora do artigo) do $6^{\circ}$ e $7^{\circ}$ anos do ensino fundamental, que sempre trabalhou com resolução de problemas, para apresentar os registros de seus alunos para os licenciandos.

A proposta que apresentamos aos futuros professores, mesmo que no ensino remoto, foi conhecer resoluções de estudantes do ensino fundamental II; aprender sobre a diversidade de caminhos que um mesmo problema pode ter para se chegar à resposta e vivenciar a resolução de problemas como metodologia de ensino.

Já o objetivo desse artigo foi problematizar diferentes formas de resolução, estando em um ambiente virtual, a partir dos registros propostos pelos licenciandos em matemática e estudantes do ensino fundamental. Ao problematizar as resoluções dos envolvidos, oportunizamos a compreensão de uma transformação dessas resoluções, pois, além de 


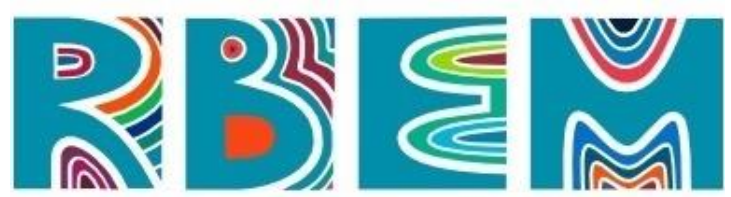

REVISTA BAIANA DE EDUCAÇÃO MATEMÁTICA

identificarmos modos de resolver por parte dos licenciandos, podemos discutir se esses são parecidos com os modos de resolver dos estudantes do $6^{\circ}$ e $7^{\circ}$ anos; quais estratégias procedimentais recorreram (algébrica, numérica, pictórica); qual seria mais adequada para ensinar de acordo o ano escolar.

Sendo assim, apresentamos o texto em 5 seções: Resolução de Problema como metodologia de ensino; Procedimentos Metodológicos; Diferentes estratégias para resolução dos estudantes do ensino fundamental II; Diferentes modos de resolução dos licenciandos e as Considerações Finais.

\section{Resolução de Problemas enquanto metodologia de ensino}

A busca por estratégias no ato de resolver problemas acontece indistintamente, faz parte do cotidiano, seja para resolver situações no trabalho, em casa, desafios do dia a dia, seja também quando utilizada na Escola. A busca por estratégias diante de desafios propostos pela escola, foca na resolução de problemas, enquanto metodologia de ensino, a fim de potencializar os processos de ensino e de aprendizagem, nas aulas de Matemática.

Podemos destacar a definição, apresentada por Hiebert, sobre o que é um problema:

Um problema é definido como qualquer tarefa ou atividade na qual os estudantes não tenham nenhum método ou regra já receitados ou memorizados e nem haja uma percepção por parte dos estudantes de que haja um método "correto" específico de solução (HIEBERT, 1997 apud WALLE, 2009, p. 57).

A resolução de um problema é uma forma ou método para chegar à solução, ou seja, como o estudante ou professor resolveu o problema para chegar à solução. Partimos do pressuposto que ao propor um problema podemos explorar diversas formas de revolvê-lo, seja recorrendo ao desenho, a escrita, a parte algébrica, geométrica, numérica, uma mescla de duas ou mais dessas formas ou ainda, várias estratégias utilizando uma dessas formas.

Explorar a variação de estratégias ou formas produzidas por estudantes e/ou professor, pode se constituir em uma metodologia de ensino. Diniz (2001) conceitua como sendo perspectiva metodológica, ou seja, uma forma de ver um problema que será investigado. Nessa perspectiva, além de propor a situação e resolvê-la, também se questiona as respostas e a própria situação. Conteúdo e metodologia se entrelaçam, estando presentes na parte do 


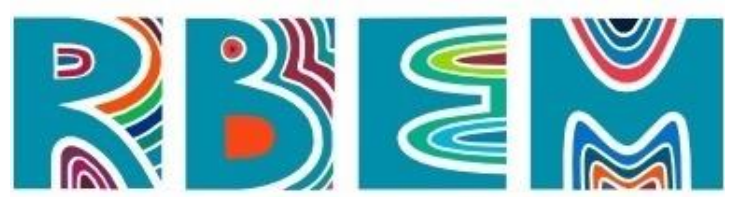

REVISTA BAIANA DE EDUCAÇÃO MATEMÁTICA

conteúdo as habilidades necessárias para resolver um problema: ler, escrever, argumentar, fazer representações, dentre outras.

A forma de comunicar as resoluções pode ser um recurso para o professor conhecer como seus estudantes estão compreendendo o conteúdo, que habilidades estão desenvolvendo e como planejar as próximas aulas, compondo parte da metodologia.

Trabalhar na perspectiva metodológica da Resolução de Problemas, em um ambiente que contemple a comunicação, não inclui experimentações eventuais, nem permite o improviso ou a falta de clareza quanto ao conhecimento matemático e a forma adequada de utilização da metodologia. (DINIZ, 2001, p. 97).

E como planejar e implementar aulas, cuja forma de trabalhar a situação-problema é investigando-a, problematizando-a, em um ambiente virtual? Como utilizar recursos que promovam ou facilitem a comunicação?

A inserção de novas tecnologias computacionais de comunicação veio favorecer o desenvolvimento dos ambientes virtuais de aprendizagem, como novos meios de apoio ao aprendizado de forma não presencial. Assim, a importância destes ambientes como ferramenta de comunicação para trocas de informações, interação e socialização são de grande valia para o cenário atual. Todavia, um sistema ou ferramenta por si só não faz o aprendizado acontecer. O professor, mediador, tem papel fundamental na orientação do processo. É ele o responsável por estimular e conduzir a turma.

Uma aula pautada nas diferentes formas de resolver e comunicar problemas, planejada para um ambiente virtual apresenta como papel do professor, de forma semelhante a presencial, aquele que medeia as discussões dos estudantes e/ou grupos, favorecendo um ambiente que iniba o rápido abandono do problema e a espera pela solução, e incentive a tentativa de esboçar alguma ideia, pois ele sabe que vale a pena dizer até onde conseguiu, em que parte teve dificuldade ou apresentar sua forma de chegar a uma solução.

A forma que conduzimos as aulas, tendo a resolução de problemas como metodologia, se baseou em Diniz (2001) e em Onuchic e Allevato (2011). De forma resumida, destacamos que, para Diniz (2011), o planejamento precisa assegurar um ambiente que contemple a escrita individual e momentos coletivos, para que individualmente ou em grupo exponham suas ideias, ouçam as dos demais. O registro individual ou do grupo comunicará a compreensão ou não do problema bem como revelará o domínio de conteúdos e habilidades. 


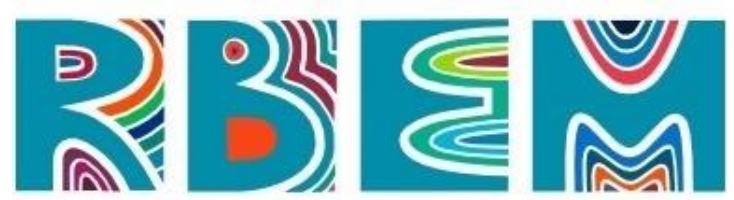

REVISTA BAIANA DE EDUCAÇÃO MATEMÁTICA

Onuchic e Allevato (2011) propõem um roteiro contendo nove itens, que explicaremos a seguir:

- Preparação do problema - o professor seleciona um problema com o intuito de construir um conceito matemático, que ainda não tenha sido ensinado aos estudantes;

- Leitura individual - é solicitado que cada aluno faça a leitura do problema;

- Leitura em conjunto - depois de formar os grupos, faz-se a leitura novamente do problema;

- Resolução do problema - os grupos, então, partem para uma resolução com os conhecimentos que possuem;

- Observar e incentivar - é papel do professor acompanhar como que cada grupo está fazendo para propor uma estratégia de resolução e mediar à medida que perceber dificuldades ou equívocos. Essa mediação ou incentivo pode ser por meio de perguntas ou de contraexemplos;

- Registro das resoluções na lousa - um dos estudantes de cada grupo registra na lousa a forma com que seu grupo resolveu o problema;

- Plenária - todos os estudantes são convidados a analisarem as resoluções expostas na lousa. Nessa análise, os estudantes podem apreciar quais estão erradas e localizar o erro, quais estão corretas e ainda, identificarem qual é a mais curta, mais longa, de fácil compreensão, mais difícil, dentre outros adjetivos;

- Busca do consenso - nesta etapa, busca-se com a turma eleger a melhor resolução, apresentando os argumentos;

- Formalização do conteúdo - o professor, então, utilizando a linguagem matemática apresenta formalmente o conceito matemático que está fundamentando a resolução.

Desta forma, há uma inversão na forma de ensinar do professor, pois "nesta metodologia, os problemas são propostos aos alunos antes de lhes ter sido apresentado formalmente, o conteúdo matemático necessário ou mais apropriado à sua resolução [...]" (ONUCHIC; ALLEVATO, 2011, p. 85). Quando apresentamos essa forma de ensinar aos licenciandos, houve um choque e uma resistência, pois aprenderam de forma contrária, primeiro se define, depois exemplifica-se e resolve-se um problema ou exercício para que seja aplicada a definição apresentada (ensinar para resolver problema).

Uma forma de mostrar que a metodologia por meio da resolução de problemas pode ser eficaz até mais que a metodologia "ensinar para resolver problema", em nossa opinião, é fazendo com os licenciandos essa construção e desafiando-os a planejarem suas aulas 


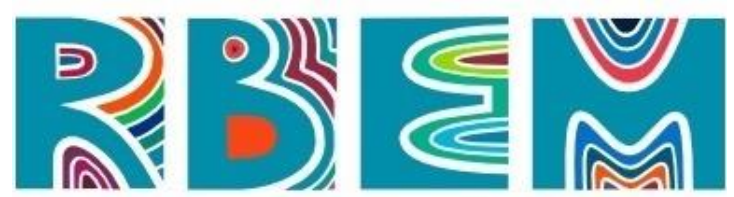

REVISTA BAIANA DE EDUCAÇÃO MATEMÁTICA

recorrendo a metodologia de ensino "ensinar por meio (através) da resolução de problemas".

Mostrar aos licenciandos que o professor precisa deixar de ser o protagonista da aula e possibilitar que os estudantes tenham maior participação no processo de aprendizagem. É o que nos confirmam Onuchic e Allevato (2011), Smole e Diniz (2001) quando destacam que aprender diferentes formas de resolver um problema aumenta o repertório dos estudantes quanto a estratégias de resoluções e compreensão de conhecimentos matemáticos; trabalha com a crença de que os estudantes são capazes de aprender matemática, constrói confiança, autoestima e desenvolve atitudes favoráveis à matemática; permite construções mais elaboradas sobre os processos de resolução. E, em relação ao professor, esses percebem que a formalização de conceitos matemáticos passa a fazer mais sentido para os estudantes quando utilizam-se da metodologia de resolução de problemas.

\section{Procedimentos metodológicos}

Essa pesquisa é de abordagem qualitativa, devido a natureza dos dados produzidos, nesse caso, as resoluções de estudantes frente a um problema selecionado de forma criteriosa, cuja explicação é feita ainda nesta seção.

Participaram da experiência, que ora registramos, as autoras que são professoras das aulas ministradas, estudantes do $5^{\circ}$ semestre do curso de licenciatura em matemática e estudantes do $6^{\circ}$ e $7^{\circ}$ anos de uma escola particular em um município na Bahia.

Os 11 estudantes universitários, licenciandos em matemática, dispunham em sua maioria de computador, mas um aluno tinha garantido apenas o aparelho celular. A internet nem sempre é de boa qualidade. Os licenciandos tinham como professora da disciplina Estágio Supervisionado I, a primeira autora deste trabalho, que ministra aulas de estágio há mais de 10 anos, sendo essa a primeira experiência com o estágio de forma remota e na modalidade extensão.

Já os estudantes da escola particular, 17 eram do $6^{\circ}$ ano e 12 do $7^{\circ}$ ano. Tinham como recursos disponíveis computador (maioria) e celular. A professora de matemática desses estudantes é a segunda autora que trabalha com turmas do ensino fundamental II há mais de 10 anos. 


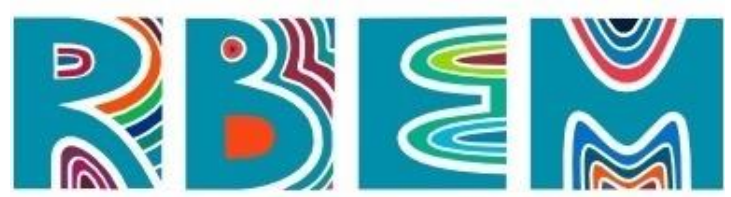

REVISTA BAIANA DE EDUCAÇÃO MATEMÁTICA

Selecionamos um problema, proposto em 2002 em uma prova de questões abertas para estudantes da $4^{\mathrm{a}}$ e $8^{\mathrm{a}}$ séries do ensino fundamental e $3^{\circ}$ ano do ensino médio do Paraná e analisada por Santos e Buriasco (2008). Esses pesquisadores tinham por objetivo investigar a produção escrita dos estudantes. Segundo Santos e Buriasco (2008) a produção escrita revela o conteúdo matemático recorrido pelo estudante assim como erros e dificuldades ao resolverem problemas. E nós, queríamos identificar estratégias que nossos estudantes, incluindo os licenciandos, poderiam propor ao resolverem o mesmo problema.

O problema selecionado tem como enunciado: "Um carteiro entregou 100 telegramas em 5 dias. A cada dia, a partir do primeiro, entregou 7 telegramas a mais que no dia anterior. Quantos telegramas entregou em cada dia?" (SANTOS, BURIASCO, 2008, p. 19).

Para melhor entendimento didático vamos apresentar um quadro contendo as etapas do roteiro (ONUCHIC; ALLEVATO, 2011) e como cada uma das professoras fizeram com seus estudantes, estando em ambientes virtuais.

Quadro1: Roteiro da aula utilizando a RP como metodologia de ensino em ambiente virtual

\begin{tabular}{|c|c|c|}
\hline Etapas do roteiro: & Professora dos licenciandos: & Professora do $6^{\circ}$ e $7^{\circ}$ anos: \\
\hline Leitura individual & $\begin{array}{l}\text { Cada aluno fez a leitura individual do } \\
\text { problema. }\end{array}$ & $\begin{array}{l}\text { Proposto aos estudantes como um } \\
\text { desafio, uma tarefa extra. }\end{array}$ \\
\hline $\begin{array}{l}\text { Leitura em } \\
\text { conjunto }\end{array}$ & $\begin{array}{l}\text { Dividimos os grupos e estes se reuniram em } \\
\text { links (salas virtuais) separadamente. }\end{array}$ & não foram organizados em grupo. \\
\hline $\begin{array}{l}\text { Resolução do } \\
\text { Problema }\end{array}$ & Cada grupo resolveu a questão. & $\begin{array}{l}\text { A professora pediu que enviassem a } \\
\text { foto da resolução no google sala de } \\
\text { aula. }\end{array}$ \\
\hline $\begin{array}{l}\text { Observare } \\
\text { incentivar }\end{array}$ & $\begin{array}{l}\text { A professora entrava e saia das salas virtuais } \\
\text { para observar e incentivar o que os } \\
\text { estudantes estavam fazendo. }\end{array}$ & Não foi objetivo daquele momento. \\
\hline $\begin{array}{l}\text { Registro das } \\
\text { resoluções }\end{array}$ & $\begin{array}{l}\text { Voltamos todos para a sala geral e cada } \\
\text { grupo compartilhou a tela para mostrar como } \\
\text { resolveram a questão. }\end{array}$ & $\begin{array}{l}\mathrm{Na} \text { aula seguinte, a professora projetou } \\
\text { para todos as resoluções e cada aluno } \\
\text { foi convidado a falar sobre sua } \\
\text { estratégia de resolução. }\end{array}$ \\
\hline Plen & $\begin{array}{l}\text { Na sala geral discutimos como ensinaríamos } \\
\text { esse problema a adolescentes do } 6^{\circ} \text { e } 7^{\circ} \\
\text { anos. } \\
\text { As resoluções dos estudantes da professora } \\
\text { Kely foram socializadas com os } \\
\text { licenciandos. }\end{array}$ & $\begin{array}{l}\text { Analisaram cada uma, sendo que os } \\
\text { estudantes explicaram oralmente os } \\
\text { caminhos que percorreram até chegar } \\
\text { na resposta. }\end{array}$ \\
\hline Busca do consenso & $\begin{array}{l}\text { Discutimos quais soluções seriam mais } \\
\text { adequadas para ensinarmos aos estudantes } \\
\text { de } 6^{\circ} \text { e } 7^{\circ} \text { anos. }\end{array}$ & $\begin{array}{l}\text { Após a explanação de cada aluno, os } \\
\text { colegas fizeram observações sobre que } \\
\text { resolução apresentava um caminho } \\
\text { mais longo, que estratégia pareceu } \\
\text { mais interessante. }\end{array}$ \\
\hline $\begin{array}{l}\text { Formalização do } \\
\text { conteúdo }\end{array}$ & $\begin{array}{l}\text { Comparamos as soluções, identificamos os } \\
\text { conteúdos e conceitos que poderiam ser } \\
\text { formalizados, a partir das soluções }\end{array}$ & $\begin{array}{l}\text { Não foi formalizado um conteúdo, mas } \\
\text { a construção lógica foi destacada a } \\
\text { partir das situações de erros e acertos. }\end{array}$ \\
\hline
\end{tabular}




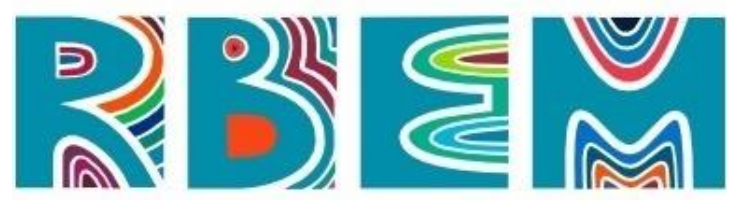

REVISTA BAIANA DE EDUCAÇÃO MATEMÁTICA

apresentadas.

Fonte: elaboração das autoras

Era objetivo da aula vivenciar a metodologia Resolução de Problemas de forma remota, em ambiente virtual, com os licenciandos. Nas aulas presenciais fazíamos os grupos, entregávamos o problema e acompanhávamos os estudantes resolvendo. Estávamos todos ali, no mesmo espaço e separados por grupos, mas acompanhando todos. E como seria em um ambiente virtual?

Fizemos os grupos, mas neste contexto cada grupo recebeu um link para se deslocar da sala geral e ir para outra sala da plataforma Meet discutir e resolver o problema. A professora podia entrar e sair dessas salas dos pequenos grupos, observar o que estavam fazendo e intervir, se necessário fosse.

Ao retornarmos para a sala geral, cada grupo tinha que apresentar sua resolução, como chegou naquela resolução e como faria se tivesse que ensinar para adolescentes do $6^{\circ}$ ou $7^{\circ}$ anos do ensino fundamental. Nesse momento não tínhamos a lousa, como é previsto no roteiro original. No ensino remoto o que tivemos foi o compartilhamento de telas e as fotos para conhecimento de cada resolução. Não tivemos como ver ao mesmo tempo todas as soluções e analisá-las juntas, como em uma lousa.

Após apresentação dos grupos dos licenciandos, iniciamos a discussão sobre como estudantes do ensino fundamental resolveriam essa questão e como fariam para ensiná-la a eles. Ensinariam usando o mesmo conteúdo e/ou estratégia que eles recorreram para resolvêla? Dando seguimento, apresentamos as resoluções dos estudantes da professora Kely e discutimos quais delas utilizaríamos para ensinar aos estudantes de $6^{\circ}$ e $7^{\circ}$ anos.

Para fazer a análise das resoluções para este artigo, utilizamos a categorização e inspiramo-nos em Cury (2007), Santos e Buriasco (2008). Após a listagem de todas as resoluções, estas foram classificadas conforme semelhanças e diferenças. As categorias emergiram da análise que fizemos das próprias resoluções. No grupo dos estudantes do ensino fundamental identificamos 3 estudantes que recorreram a estratégia de tentativa e erro sem explicar como encontraram o $1^{\circ}$ valor; outros 10 recorreram a estratégia de tentativa e erro, mas explicando como encontraram o $1^{\circ}$ valor; 8 estudantes usaram a álgebra como estratégia de solução, ou seja, recorreram a uma equação e 8 erraram. 


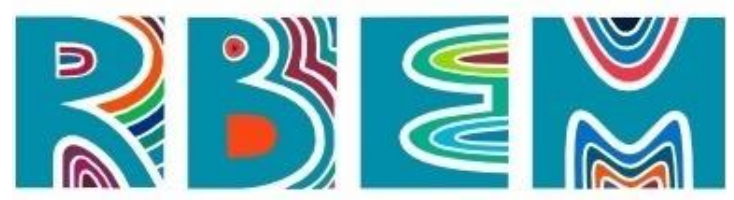

REVISTA BAIANA DE EDUCAÇÃO MATEMÁTICA

No grupo dos licenciandos identificamos que 6 que recorreram a álgebra, fazendo uso da equação; 4 fixaram um valor e 1 recorreu a Progressão Aritmética (PA).

A seguir, iremos analisar as resoluções dos alunos do ensino fundamental e depois as resoluções dos licenciandos. Exemplificaremos algumas dessas resoluções e usaremos as letras do alfabeto em substituição aos nomes dos estudantes.

Diferentes estratégias para resolução dos estudantes do ensino fundamental II

Iniciamos a análise pela categoria Tentativa e Erro, subdividida em dois grupos, com e sem explicação dos estudantes, por escrito. Salientamos que somente os estudantes do Ensino Fundamental recorreram a essa categoria. Em alguns exemplos de resoluções o erro é sinalizado com riscos, simbolizando que era para desconsiderar, conforme foram orientados, pois o erro é muito significativo, nos mostra o caminho que o estudante percorreu e por perceber que não era o adequado, ele abandona e parte para outra tentativa.

\section{Tentativa e erro}

A estratégia Tentativa e Erro é compreendida por nós como sendo aquela resolução que o estudante manipula os números com as informações que o problema fornece até encontrar os valores e responder à pergunta. Entretanto, alguns estudantes explicaram como encontraram o valor correspondente ao $1^{\circ}$ dia e outros não. A esse primeiro subgrupo categorizamos como tentativa e erro com explicação e o segundo subgrupo tentativa e erro sem explicação.

\section{Tentativa e erro com explicação}

$\mathrm{Na}$ resolução apresentada pela aluna $\mathrm{A}$, conforme figura 1, percebe-se que inicialmente ela dividiu o número de telegramas por 5, para encontrar uma quantidade que seria entregue todos os dias. Contudo, a própria estudante registra que essa quantidade (20) não poderia ser a resposta uma vez que a cada dia a quantidade aumentava. Resolve então, diminuir 7 e depois menos 7, a fim de encontrar o primeiro dia. Quando se depara com o resultado 6, percebe que não há mais como diminuir 7. Supõe então, que essa seria a quantidade de telegramas entregues no $1^{\circ}$ dia. E ainda destaca "e acabei acertando". O que indica que ela estava utilizando a tentativa. Para continuar, passou a acrescentar 7 aos outros 


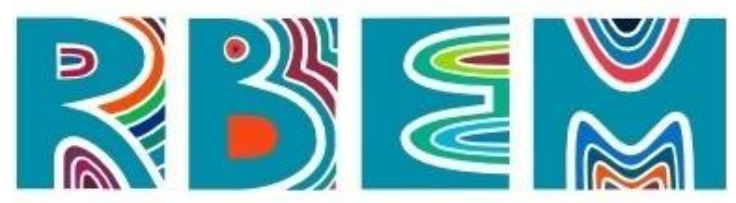

REVISTA BAIANA DE EDUCAÇÃO MATEMÁtICA

dias. Ao final, somou todos os resultados para verificar se totalizava 100. Consideramos esse procedimento bem argumentado e de muita segurança da parte da estudante A.

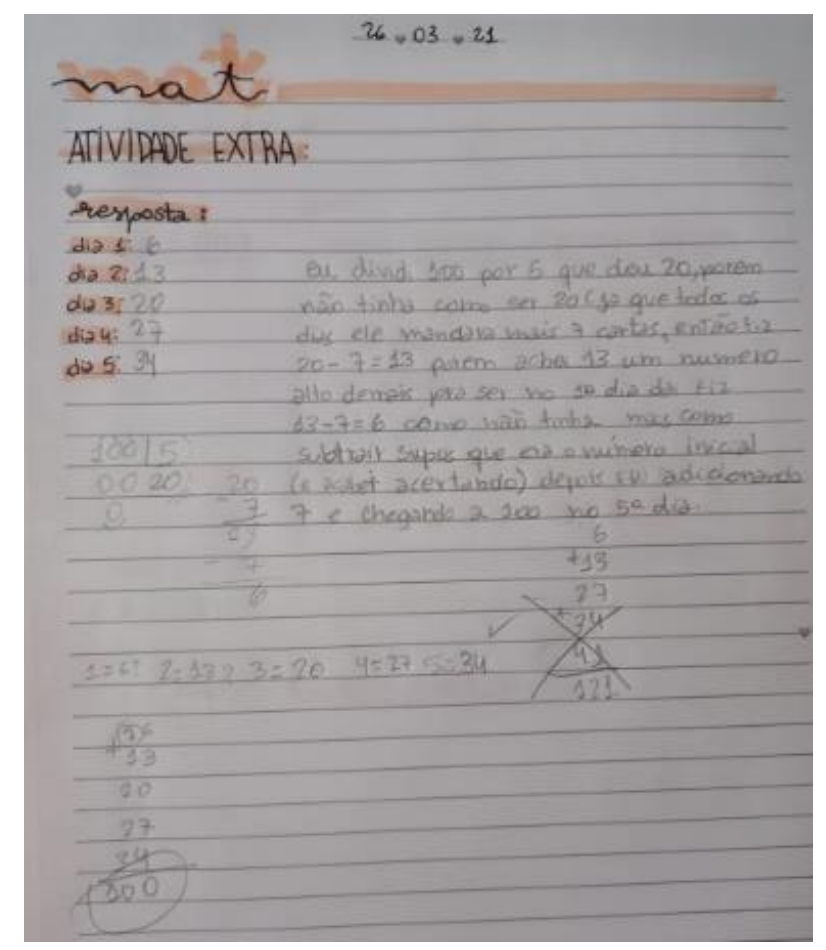

Figura 1: Resolução do estudante A

O aluno B, também usa a tentativa. Inicia supondo o primeiro dia sendo 5 telegramas e vai acrescentando 7 ao valor de 5 telegramas no $1^{\circ}$ dia. Ao final, percebeu que o resultado se aproximou do 100, todavia, faltavam 5 telegramas. Então, altera o valor de 5 para 6 e justifica que com esse valor ele chega aos 100 telegramas em 5 dias, conforme mostra a figura 2. Após apresentação, os colegas comentaram que a estratégia foi "bem pensada".

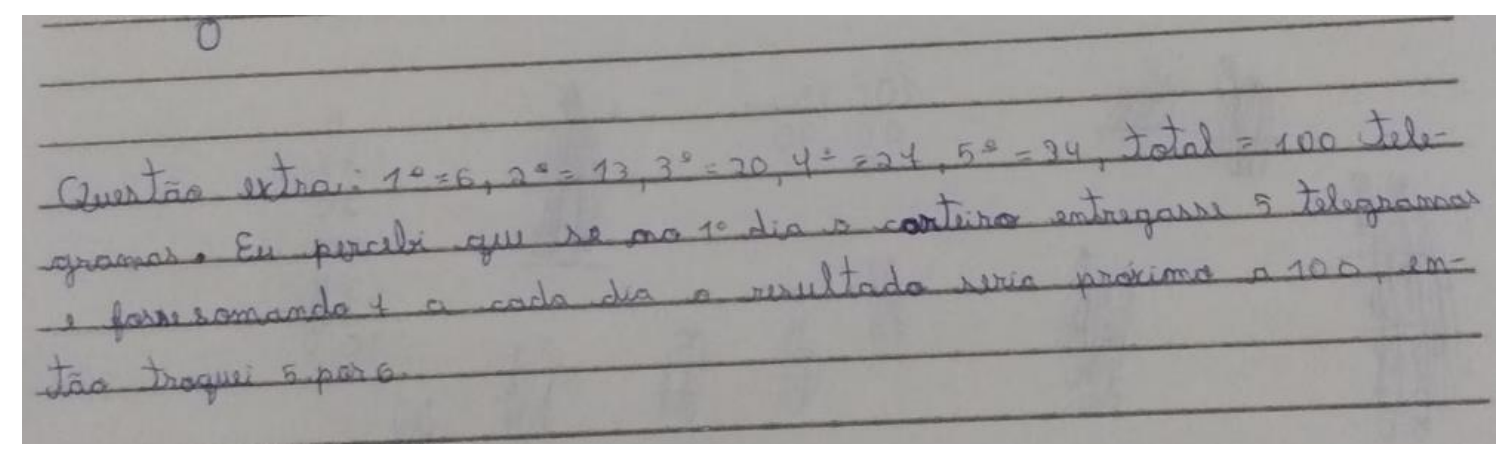

Figura 2: Resolução do estudante B 


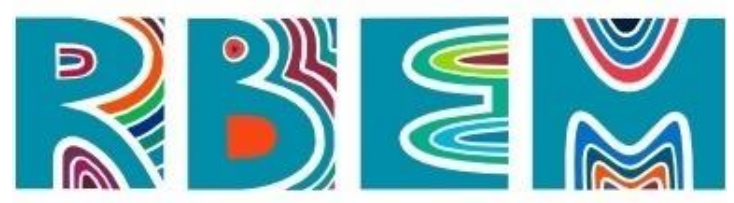

\section{Tentativa e erro sem explicação}

A resolução do estudante $\mathrm{C}$, figura 3, mostra que ele tentou, errou, passou corretivo e apesar de chamar o número referente ao primeiro dia de $\mathrm{x}$, continuou a resolução e encontrou a resposta, mas não comunicou porque alterou para 6 o valor inicial nem como chegou a ele. Da mesma forma o estudante D (figura 4) não explicou por que parte de uma estimativa de 6 para o primeiro dia e vai acrescentando 7 em cada dia seguinte.

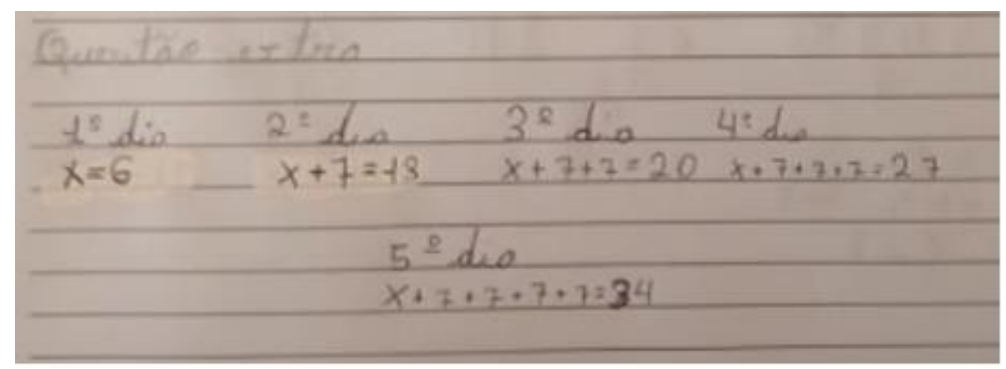

Figura 3: Resolução do estudante C

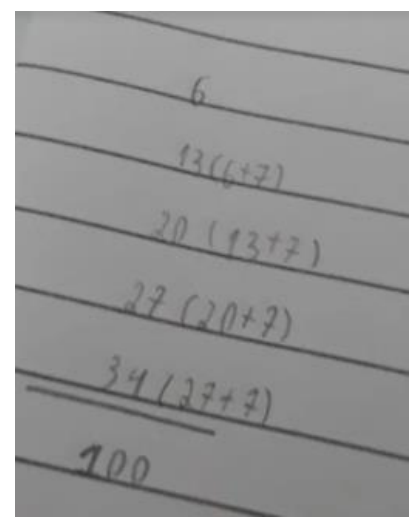

Figura 4: Resolução do estudante D

\section{Álgebra}

Nessa categoria apresentamos 3 exemplos, nos quais todos os estudantes fizeram uso de um termo desconhecido nomeado x. Contudo, são 3 diferentes resoluções. A resolução do estudante F, (figura 5) é desenvolvida utilizando uma equação de forma explícita: 5x + $70=100$. Descobre o valor de x e substitui, de forma implícita, em cada um dos dias, encontrando a quantidade de telegramas entregues por dia. 


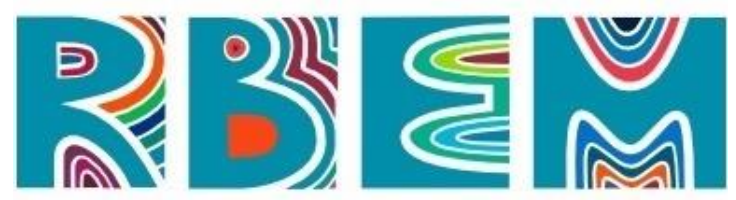

REVISTA BAIANA DE EDUCAÇÃO MATEMÁTICA

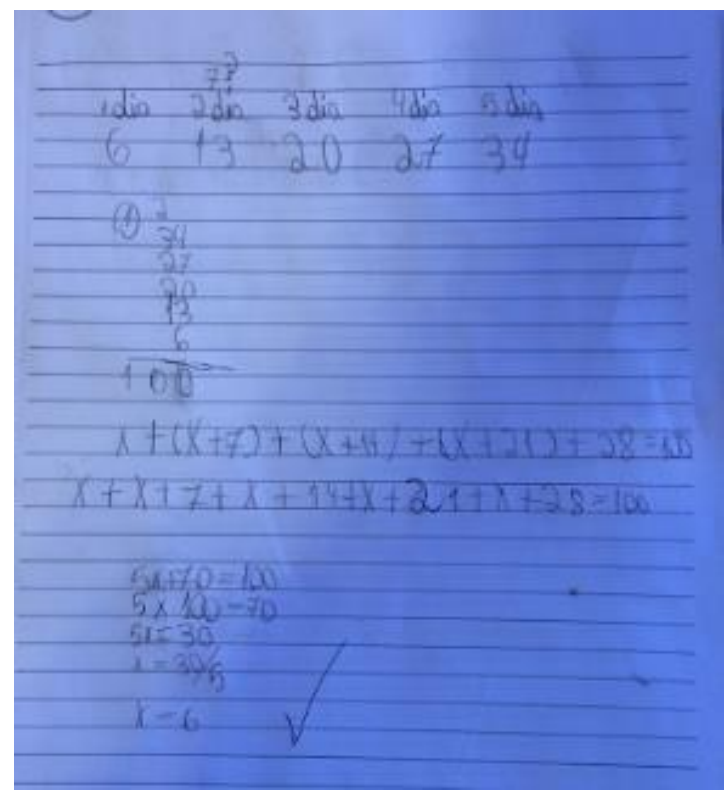

Figura 5: Resolução do estudante F

A resolução do estudante $\mathrm{G}$ é desenvolvida separando a parte numérica da variável. Ele soma todos os números encontrando 70, diminui de 100 e o resultado (30) é dividido por 5 , encontrando o valor de $\mathrm{x}$. Provavelmente porque partiu da ideia de que são 5 dias e cada $\mathrm{x}$ escrito é o valor de cada dia. Descoberto o termo $\mathrm{x}$, foi acrescentando esse valor até encontrar o quinto dia. Como prova, soma todos os valores dos dias e encontra 100 , total de telegramas entregues. Veja o final da resolução na figura 6.

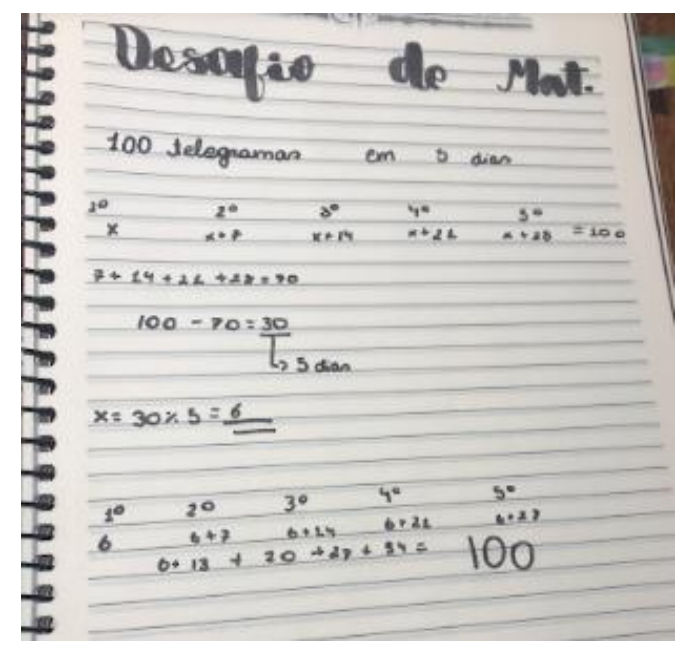

Figura 6: Resolução do estudante $G$

Já o estudante H, (figura 7), fixa o valor desconhecido “x” para cada dia e acrescenta 7 para o segundo dia, que seria $x+7$, o terceiro $x+14$ e assim por diante. Ao final percebeu que 


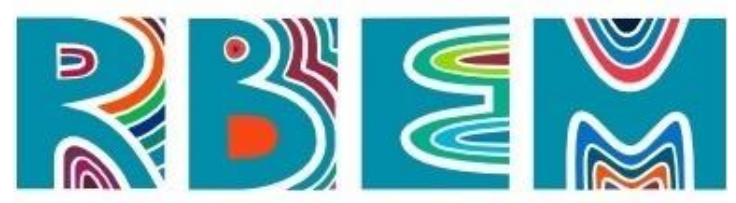

os números somavam 70. Subtraiu 70 de 100, encontrou o valor 30, sem explicar o porquê dividiu 30 por 5 e encontrou o valor 6, para cada x. Provavelmente porque são 5x, um para cada dia. Na sequência, apresentou um quadro informando a quantidade de telegramas entregues em cada dia.

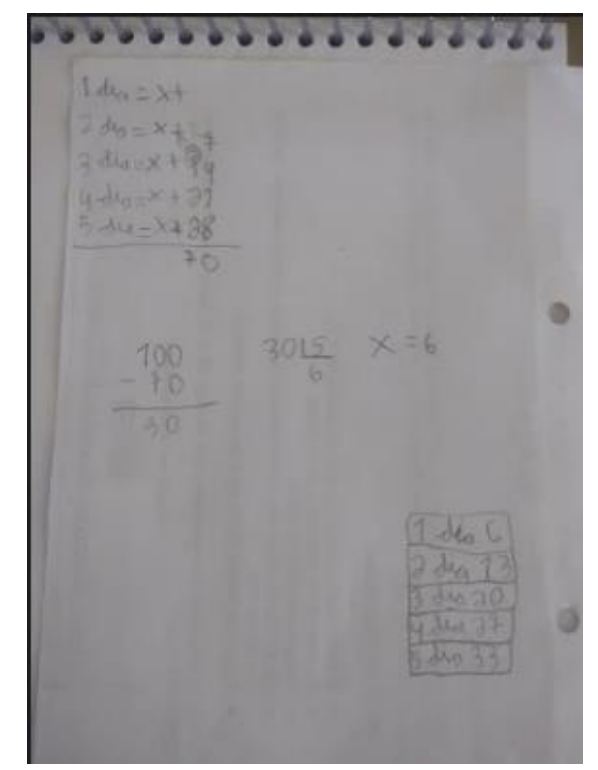

Figura 7: Resolução do estudante H

\section{Resolução equivocada}

Dos 8 estudantes que responderam de forma incorreta ao desafio, 7 utilizaram o cálculo de divisão semelhante ao aluno I. Na plenária, narraram não ter conseguido interpretar o desafio e assim optaram por calcular uma divisão utilizando números contidos no enunciado, mas não concluíram o que de fato teriam que responder. Vale destacar que destes, 5 ainda acrescentaram que tiveram pressa ao responder e só depois perceberam que não apresentaram uma resposta.

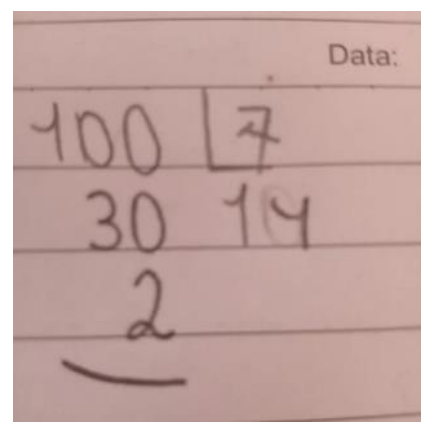

Figura 8: Resolução do estudante I 


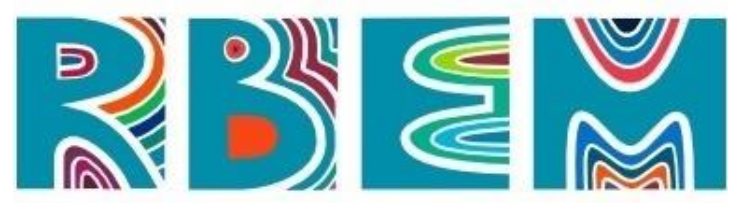

O aluno J, figura 9, não conseguiu explanar claramente o porquê de ter começado com o número 27, só apontou que escolheu esse número. É notório também a falta de atenção ao seguir para o terceiro dia, não fazendo registro do segundo. Conclui-se que não houve atenção ao que foi solicitado.

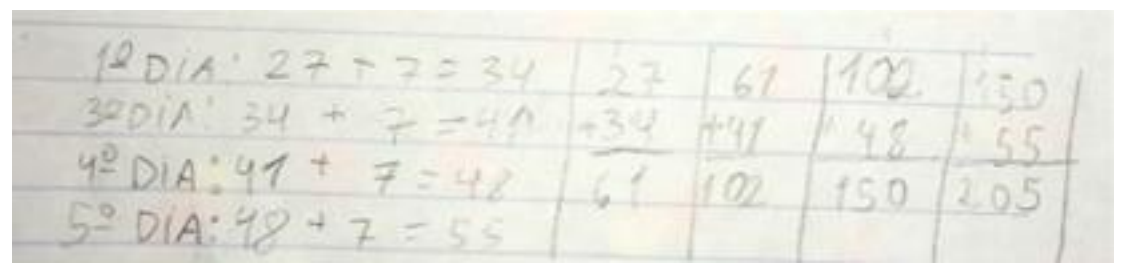

Figura 9: Resolução do estudante J

O estudante $\mathrm{K}$, apesar de ter buscado um termo central, o que de início foi uma boa estratégia (figura 10). Partiu desse número acrescentando 7, quando deveria ir diminuindo para encontrar o primeiro e segundo dias e, somando 7 para encontrar o quarto e quinto dias. Não se atentou ao final de conferir se a soma daria 100, ou seja, houve a falta de uma verificação e de atenção.

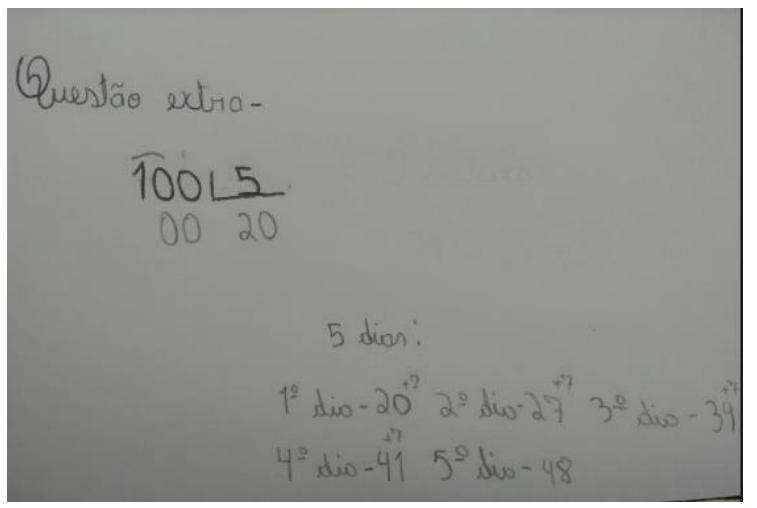

Figura 10: Resolução do estudante K

\section{Diferentes modos de resolução dos licenciandos}

\section{Álgebra}

Exemplificamos com duas resoluções esta categoria. Na resolução L a incógnita não é escrita como x, letra muito comum para representar quantidades desconhecidas. $\mathrm{O}$ estudante preferiu utilizar A, B, C, D e E para representar os 5 dias. Depois ele faz (sem explicar) a substituição das letras, embutindo as demais na letra A (figura 11). 


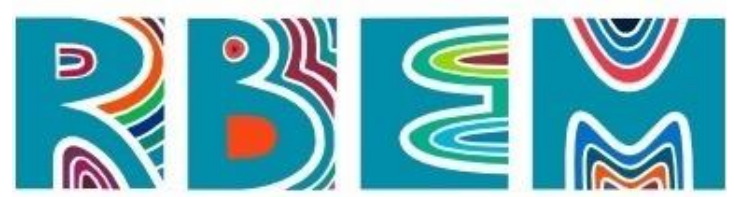

\section{$A+(A+7)+(A+14)+(A+21)+(A+28)=100$}

Figura 11: parte da resolução do estudante L

Com a equação acima o estudante encontra o valor de $\mathrm{A}$ e assim as demais quantidades de telegramas, conforme a figura 12.

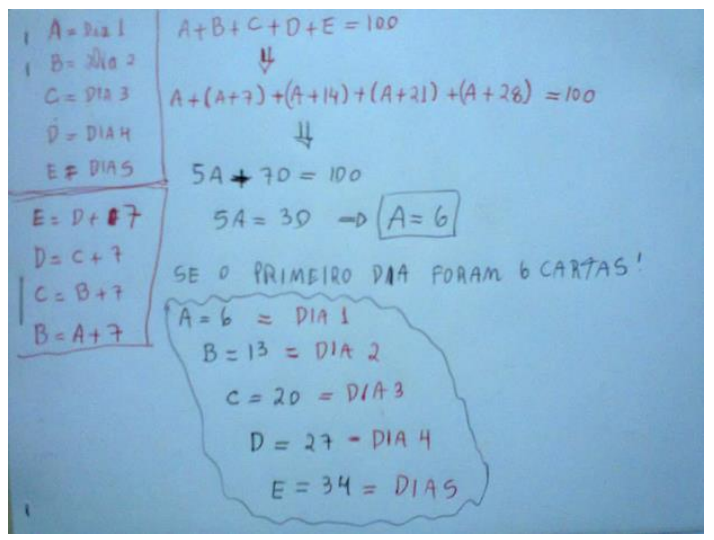

Figura 12: Resolução completa do estudante L

Na resolução do grupo MNOP, eles utilizaram a letra x embutida em todos os dias. Por meio da equação encontraram quantos telegramas são entregues nos 5 dias.
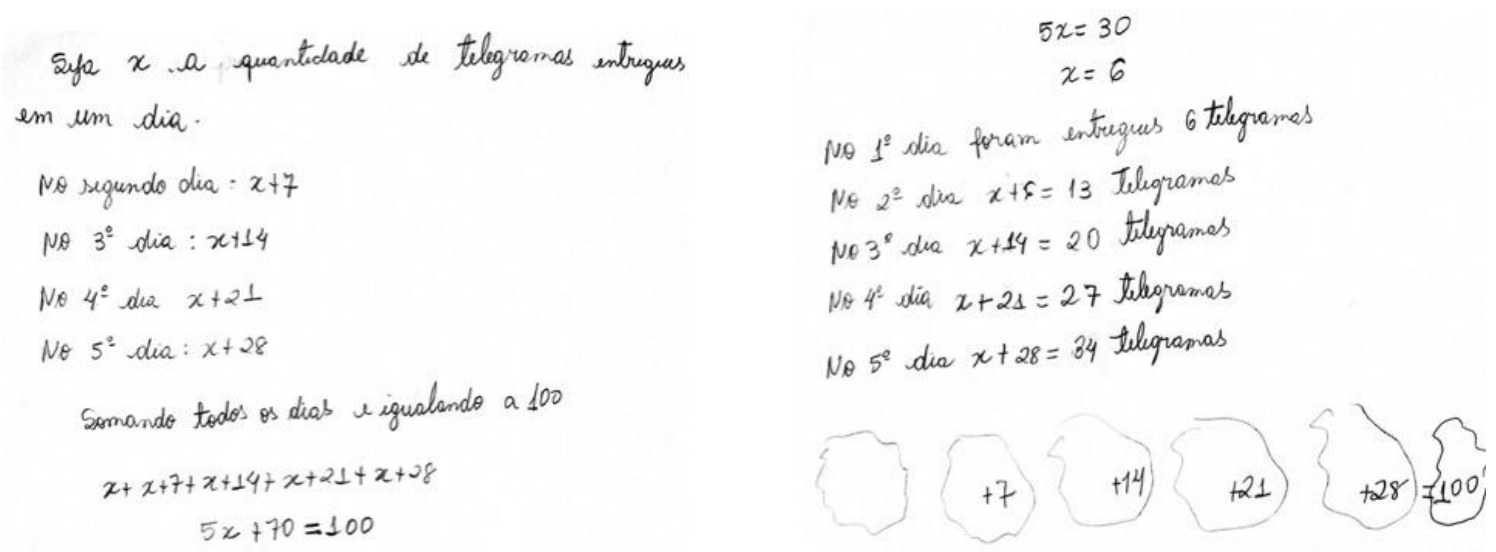

Figura 13: Resolução do grupo MNOP

Esse grupo foi o único que fez um esboço gráfico. O que nos chama atenção é que o desenho não é um recurso utilizado por licenciandos, mas pode ser um recurso muito importante para ensinar os estudantes. Esse indicativo nos chama atenção, pois disciplinas como estágios e práticas como componente curricular precisam trabalhar formas de resolver problemas como se fossem ensinar. Ao fazer essa provocação os licenciandos não sabiam como explicar aos estudantes se não recorrendo a forma que cada um utilizou. 


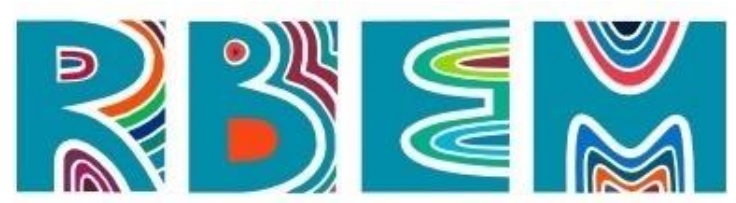

\section{Fixando um valor}

Apresentamos 3 resoluções, sendo que a estratégia se subdividiu em duas formas de fixar um valor. A primeira foi quando o estudante fixou o valor 20 e a segunda foi quando estudantes fixaram o valor 6. Vamos começar pela resolução do estudante $Q$, conforme figura 14.

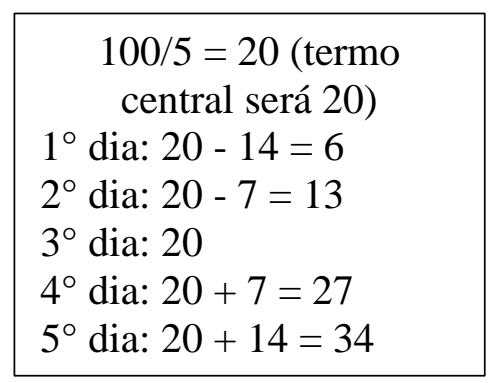

Figura 14: Resolução do estudante Q

Essa estratégia foi chamada pelo próprio estudante de termo central, que no caso se refere ao valor 20, que está fixo e distribuído nos 5 dias de entrega. Como o estudante descobriu as variações que aconteceram entre os dias, ele nos escreveu: "como são 100 cartas em 5 dias, eu imaginei que eu teria uma quantidade que estaria no centro e as outras quando eu diminuísse em um dia, eu aumentava no outro da frente para ficar equilibrado. Porque os dias não têm a mesma quantidade de cartas".

Encontrando o que ele chamou de termo central, ele manipulou somando ou subtraindo valores múltiplos de 7. O termo central sofre as variações (com múltiplos de sete) aumentando - depois do $3^{\circ}$ dia, ou diminuindo - antes do $3^{\circ}$ dia. Um exemplo de manipulação numérica.

A segunda forma de fixar um valor, neste caso o 6 , foi apresentada em duas resoluções de maneiras diferentes. A primeira pode ser contemplada na figura 15, conforme resolução do estudante R. 


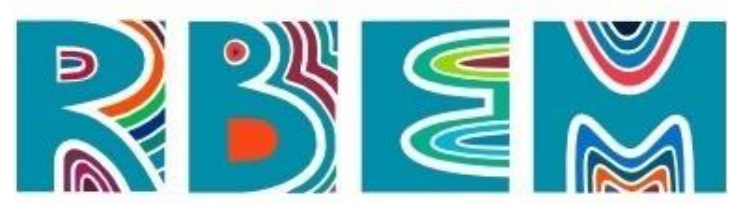

REVISTA BAIANA DE EDUCAÇÃO MATEMÁTICA

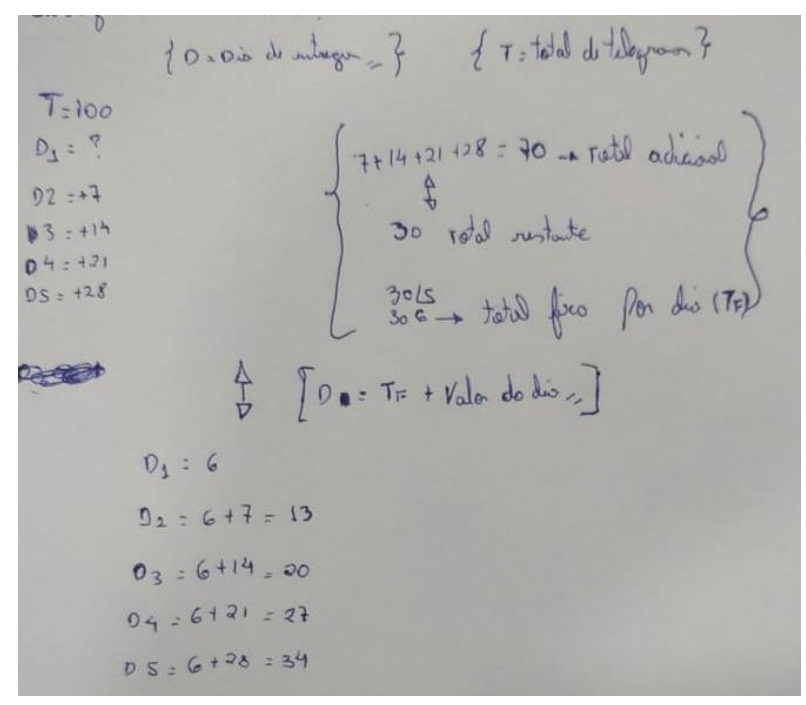

Figura 15: Resolução do estudante R

Primeiro ele registra os dias (representando por $\mathrm{D}_{1} \ldots \mathrm{D}_{5}$ ) seguidos da quantidade de telegramas que o problema informa. Em seguida, soma todos os valores numéricos e encontra como resultado 70, identificando que faltam 30 telegramas para entrega. Até então, ele é o primeiro a pensar no valor 30 como faltando para entrega.

Temos que 30 telegramas faltam para ser entregues, em 5 dias. Então, ele dividiu 30 por 5 e encontrou a quantidade de telegramas que é fixa por dia, no caso, 6. Podemos ver no final de sua resolução o valor 6 fixado e os demais valores que o problema fornece que são entregues e em quais dias.

A resolução de $S$ (figura 16) também mostrou a manipulação numérica, porém parte dessa manipulação foi chamada pela estudante de múltiplos de sete. Ela sabe que a cada dia 7 telegramas são entregues a mais que no dia anterior, exceto no $1^{\circ}$ dia, então escreveu: "somando os 5 primeiros múltiplos de sete) temos: $0+7+14+21+28=70 "$ " Somando esses valores temos 70 telegramas entregues, faltando 30. Ela também percebeu e identificou os 30 telegramas como faltando 30 para entregar.

Então, ela usa a estratégia de dividi-los igualmente entre os cinco dias, encontrando 6 telegramas para cada dia. No final ela fixou o valor 6 e foi acrescentando os múltiplos de 7. 


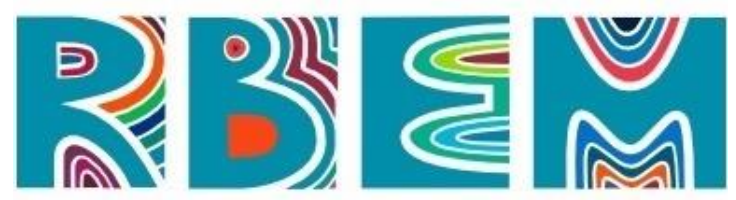

REVISTA BAIANA DE EDUCAÇÃO MATEMÁTICA

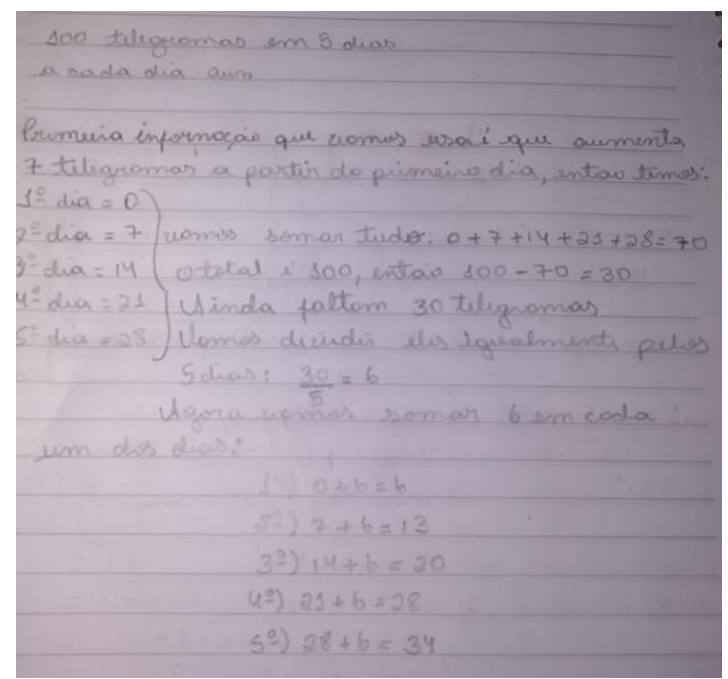

Figura 16: Resolução de $S$

No $3^{\circ}$ dia, quando somou $14+6$, encontrou 20 , o valor central citado na resolução do estudante Q.

\section{Progressão aritmética}

Essa resolução foi a que mais chamou atenção de todos em sala. Ele percebeu que a soma dos 5 elementos era 100 e que a razão era 7 , já que a cada dia 7 telegramas a mais eram entregues - daí a razão de ser uma progressão aritmética. Informações suficientes para que usando a expressão do último termo e da soma de uma PA, encontrasse o primeiro e o último termos ou, os elementos, como ele mencionou na resolução, conforme figura 17.

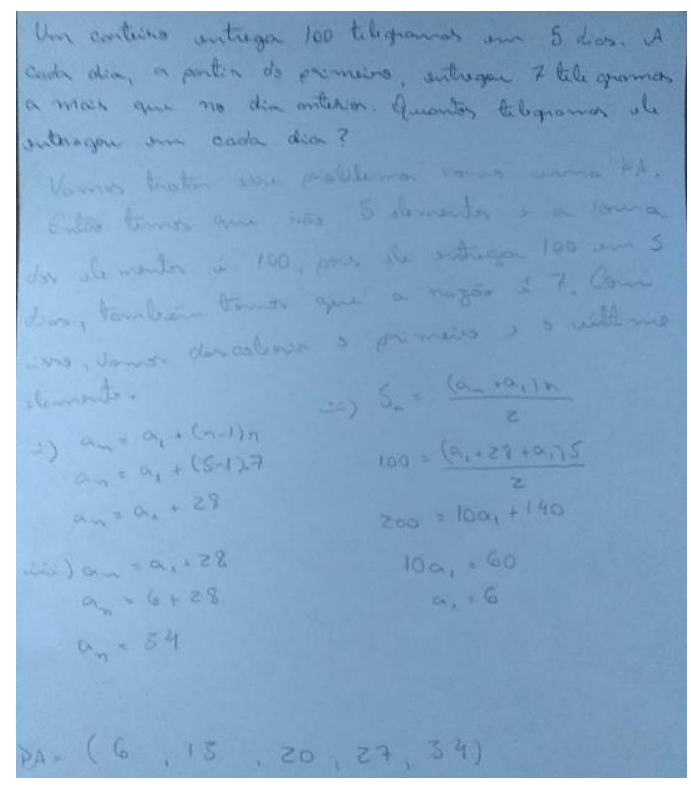

Figura 17: Resolução de T 


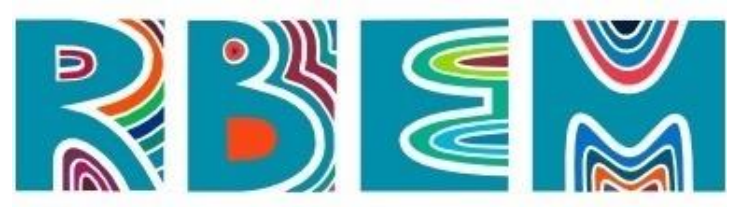

REVISTA BAIANA DE EDUCAÇÃO MATEMÁTICA

Depois de apresentada à turma, os estudantes disseram: "por que eu não pensei nisso"; "É mesmo, é uma PA"; "Eu nunca imaginaria essa solução". Mais uma vez, fica demonstrado o quão é importante darmos a chance de cada um resolver um problema a sua maneira e mais ainda, de socializarmos as diferentes formas encontradas.

É possível afirmar que há um estímulo para que na próxima vivência com resolução de problemas se tente algum caminho para encontrar uma possível resposta ao problema proposto. Vendo a diversidade de formas, eles podem se arriscar e tentar não desistir. Percebem que podem utilizar a escrita, seja numérica, algébrica ou a própria linguagem materna para comunicar a estratégia pensada.

Importante destacar que essa forma (P.A.) não seria possível de ensinar para os alunos da professora Kely, uma vez que ainda estavam no $6^{\circ}$ ou $7^{\circ}$ ano. Apresentar diferentes formas de resolver a questão proporcionou, especialmente ao licenciando $\mathrm{T}$, refletir e conhecer outras formas de resolver o problema e se atentar a "como" ensiná-lo para estudantes que não estão no ensino médio, por exemplo.

\section{Considerações finais}

Quando o aluno se utiliza da comunicação para expressar sua resolução, ele demonstra que compreendeu o problema e que tem um caminho a seguir para encontrar uma possível solução. Se esta estiver correta, ele alcançou o objetivo proposto. Se estiver errada dá ao professor a possibilidade de conhecer onde pode intervir para que o aluno retome e apreenda o conceito ou a operação necessária. Avaliação constante, tanto para professor quanto para o estudante, rompendo com a ideia de que tem data e hora marcadas, quando utilizamos de um instrumento avaliativo programado.

A forma com que os estudantes explicaram ou fizeram os cálculos (comunicação) nos deram pistas para compreender e produzir as categorias de análise. O tipo de categoria, se deu conforme as estratégias de resolução. Temos estudantes do ensino fundamental II e da licenciatura em matemática, cuja estratégia de solução são parecidas e outras bem diferentes, devido ao conhecimento matemático adquirido e mobilizado para resolver o problema. É o caso da PA, conteúdo trabalhado no ensino médio, mas que apenas um aluno da licenciatura recorreu como resolução para o problema. 


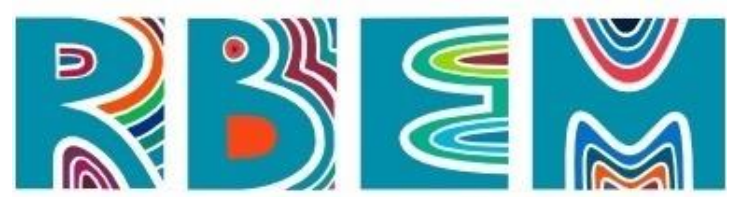

REVISTA BAIANA DE EDUCAÇÃO MATEMÁTICA

Contudo, identificamos estratégias semelhantes entre alguns estudantes do ensino fundamental e superior. Como é o caso da resolução A (estudante do ensino fundamental) e da resolução Q (futuro professor). Ambos partem da ideia inicial de que existe um valor como “central”, dividindo 100 por 5 , encontrando o 20. A percepção matemática dessa estudante é tamanha que ela diz: "não tinha como ser 20, já que todos os dias ele mandava mais 7 cartas, então fiz 20-7=13, porém 13 é um número alto demais para ser no $1^{\circ}$ dia, daí fiz $13-7=6$, como não tinha mais como subtrair supus que era o número inicial [...]", o que justificou agrupar como tentativa e erro. Já o estudante Q, afirmou que existiria uma quantidade que estaria no centro e as outras que ele poderia aumentar em um dia e diminuir no outro, até que chegasse ao $5^{\circ}$ dia.

O estudante K (ensino fundamental) também percebeu que haveria um valor fixo (20), porém ao contrário da estudante $\mathrm{A}$, ele apenas somou 7 aos dias seguintes, sem perceber que ultrapassava os 100 telegramas em 5 dias.

A percepção de que há um valor fixo, ora 20 ora 6, nos fez construir essa categoria, que vale apena analisá-la com mais detalhes a partir das resoluções dos estudantes Q, R e S (todos licenciandos). A forma de desenvolver e argumentar é que demarcou a diferença nas resoluções, tendo como princípio - fixar um valor.

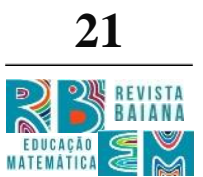

\begin{tabular}{|l|l|l|}
\hline Resolução de Q: & Resolução de R: & Resolução de S: \\
$1^{\circ}$ dia: $20-14=6$ & $D_{1}=6$ & $\left.1^{\circ}\right) 0+6=6$ \\
$2^{\circ}$ dia: $20-7=13$ & $D_{2}=6+7=13$ & $\left.2^{\circ}\right) 7+6=13$ \\
$3^{\circ}$ dia: 20 & $D_{3}=6+14=20$ & $\left.3^{\circ}\right) 14+6=20$ \\
$4^{\circ}$ dia: $20+7=27$ & $D_{4}=6+21=27$ & $\left.4^{\circ}\right) 21+6=27$ \\
$5^{\circ}$ dia: $20+14=34$ & $D_{5}=6+28=34$ & $\left.5^{\circ}\right) 28+6=34$ \\
\hline
\end{tabular}

Embora as resoluções R e S tenham fixado o valor 6, eles trabalharam com argumento diferente para sustentar a estratégia escolhida, a ideia dos múltiplos de 7 , é o que utiliza a estudante $\mathrm{S}$.

Podemos inferir que os licenciandos tinham a seu favor, um conhecimento matemático muito maior que os estudantes do ensino fundamental II, porém em nada seus registros deixaram a desejar, pois quando não tinham a técnica ou conhecimento matemático (linguagem matemática) eles usaram a lógica e comunicaram suas estratégias recorrendo a linguagem materna. 


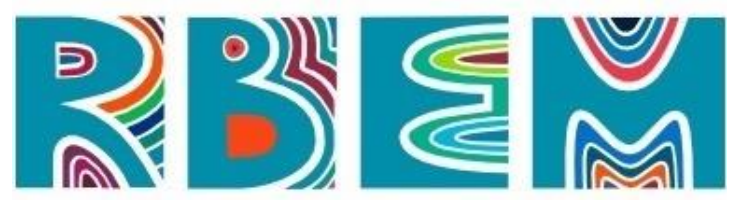

REVISTA BAIANA DE EDUCAÇÃO MATEMÁTICA

Contudo, recorrer a linguagem materna, cálculos, esquemas, quadros, equações são recursos que precisam ser desenvolvidos e estimulados em sala de aula, pelo professor. Incentivar que utilizem diversas formas para resolver um problema e socializá-las são estratégias de ensino valiosas, pois amplia o repertório de soluções e desperta no futuro professor a possibilidade de incentivar estudantes a encontrar outras formas de resolver um determinado problema, rompendo com a ideia de que a resolução é única. Além disso, possibilita que o estudante seja construtor do seu próprio conhecimento matemático.

A metodologia de ensino resolução de problemas, pode ser incentivada e desenvolvida tanto no ensino presencial como no remoto. Utilizando o roteiro proposto por Onuchic e Allevato (2011) destacamos que é possível segui-lo, fazendo ajustes, como: 1) a divisão de grupos não se dá no mesmo espaço físico, mas no espaço virtual, em que cada grupo se dirige a uma sala por meio de um link; 2) O professor poderá observar e incentivar os estudantes, entrando nas salas virtuais para acompanhar o trabalho; 3) Registrar as resoluções na lousa, neste caso é substituída por registrar as resoluções em tela, pois podemos, antecipadamente, agrupar todas as resoluções e projetar aos estudantes e/ou enviar uma foto com todas elas. $\mathrm{O}$ que não significa mandar foto de cada solução, pois a ideia é ter uma visão de todas as resoluções ao mesmo tempo; 4) a busca pelo consenso pode se dar um pouco diferente, pois em ambiente virtual, precisamos a todo instante pedir para abrirem pelo menos o microfone para ouvir os estudantes; 5) a formalização do conteúdo também é possível de ser feita, porém destacamos que aquela avaliação que o professor pode fazer olhando cada um dos seus estudantes e tentando captar por meio de suas fisionomias se estão ou não entendendo, fica a desejar.

O tipo de problema a ser trabalhado com os estudantes também é muito importante e fez toda diferença para o desenvolvimento dessa metodologia de ensino. Esperamos que professores e licenciandos possam fazer uso dessa metodologia estejam no ensino presencial ou remoto, na educação básica ou em disciplinas como estágios supervisionados.

\section{Referências}

CURY, H. N. Análise de Erros: o que podemos aprender com as respostas dos alunos. Belo Horizonte: Editora Autêntica, 2007. 


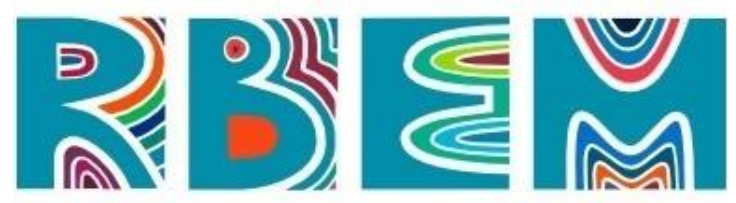

DINIZ, Resolução de Problemas e comunicação. In: SMOLE, K. S.; DINIZ, M. I. (org.). Ler, escrever e resolver problemas: habilidades básicas para aprender matemática. Porto Alegre: Artmed Editora, 2001. P. 87- 97.

ONUCHIC, L. R.; ALLEVATO, N. S. G. Pesquisa em Resolução de Problemas: caminhos, avanços e novas perspectivas. Bolema, Rio Claro (SP), v. 25, n. 41, p. 73-98, dez. 2011.

SANTOS, J. R. V.; BURIASCO, R. L. C. Uma análise interpretativa da produção escrita em matemática de alunos da escola básica. Zetetiké, Campinas (SP), v. 16, n. 30, p. 11- 43, jul./dez. 2008.

SMOLE, K. S.; DINIZ, M. I. Ler, escrever e resolver problemas: habilidades básicas para aprender matemática. Porto Alegre: Artmed Editora, 2001.

WALLE, J.A.V. Matemática no ensino Fundamental: formação de professores e aplicação em sala de aula. 6 ed. Porto Alegre: Artmed, 2009.

Artigo submetido em: 30/06/2021

Artigo aceito em: 19/11/2021 